Article

\title{
Establishing a Risk Assessment Framework for Marine Assets and Assessing Typhoon Lekima Storm Surge for the Laizhou Bay Coastal Area of the Bohai Sea, China
}

\author{
Jian Li ${ }^{1}$, Dongxue Mo ${ }^{2,3,4,5, *}{ }^{\text {Rui Li }}{ }^{1} \mathbb{D}$, Yijun Hou ${ }^{2,3,4,5}$ and Qingrong Liu ${ }^{1}$ \\ 1 North China Sea Marine Forecasting Center of State Oceanic Administration, Yunling Road, 27, \\ Qingdao 266061, China; lijian_bhybzx@ncs.mnr.gov.cn (J.L.); lirui@ncs.mnr.gov.cn (R.L.); \\ liuqingrong@ncs.mnr.gov.cn (Q.L.) \\ 2 Key Laboratory of Ocean Circulation and Waves, Institute of Oceanology, Chinese Academy of Sciences, \\ Nanhai Road, 7, Qingdao 266071, China; yjhou@qdio.ac.cn \\ 3 Laboratory for Ocean Dynamics and Climate, Pilot National Laboratory for Marine Science and \\ Technology (Qingdao), Wenhai Road, 1, Qingdao 266237, China \\ 4 University of Chinese Academy of Sciences, Yuquan Road, 19A, Beijing 100049, China \\ 5 Center for Ocean Mega-Science, Chinese Academy of Sciences, Nanhai Road, 7, Qingdao 266071, China \\ * Correspondence: dongxuemo@qdio.ac.cn; Tel.: +86-532-82898873
}

check for updates

Citation: Li, J.; Mo, D.; Li, R.; Hou, Y.; Liu, Q. Establishing a Risk Assessment Framework for Marine Assets and Assessing Typhoon Lekima Storm Surge for the Laizhou Bay Coastal Area of the Bohai Sea, China. J. Mar. Sci. Eng. 2022, 10, 298. https://doi.org/10.3390/jmse10020298

Academic Editor: Alfredo

L. Aretxabaleta

Received: 17 January 2022

Accepted: 16 February 2022

Published: 21 February 2022

Publisher's Note: MDPI stays neutral with regard to jurisdictional claims in published maps and institutional affiliations.

Copyright: () 2022 by the authors Licensee MDPI, Basel, Switzerland. This article is an open access article distributed under the terms and conditions of the Creative Commons Attribution (CC BY) license (https:// creativecommons.org/licenses/by/ $4.0 /)$.

\begin{abstract}
Effective risk assessment can reduce the economic losses and physical damage caused by marine dynamic processes, such as storm surges. Most risk assessments of marine disasters are based on regional parameters and discrete hazard grades. Targeted, multilevel, and multiangle risk assessments are urgently needed. This study focuses on specific types of affected infrastructure. We established a sensitivity matrix by considering the effects of different disaster causal factors on different types of affected infrastructure. Through this matrix, hazards, vulnerability, and emergency response and recovery capability were effectively combined in a risk assessment framework. We completed the risk calculation for multiple concurrent effects of disasters in areas with superimposed key infrastructure using complementary risk superposition. The hazard grade, vulnerability grade, and coefficient of emergency response and recovery capability were established based on the means of return period, characteristics of disaster distribution, types of affected infrastructure and disaster relief distance, and were continuous by solving functions, normal cumulative distributions, and analytic functions. On the basis of reasonable MIKE21 numerical simulation and abstract spatial distribution of vulnerable assets, we tested the rationality of the assessment system in the Lekima typhoon storm surge process. The results showed that the assessment system accurately reflected the risk of damage to the important infrastructure in terms of spatial distribution. Therefore, this risk assessment framework was suitable for the assessment of a marine dynamic disaster process in the lower Laizhou Bay coastal area of the Bohai Sea, China. Moreover, it provided a reference for disaster prevention and reduction, guided the way for decision making, and effectively reduced disaster losses.
\end{abstract}

Keywords: risk assessment; storm surge; affected infrastructure; emergency response and recovery capability; Lekima

\section{Introduction \\ 1.1. Research Status}

Extreme marine weather events and their effects (storm surge, waves, etc.) are the primary cause of harm to coastal areas around the globe [1-4]. Early warning systems and disaster prevention and reduction measures are essential for ensuring the safety of people's lives and properties in coastal areas. Simple numerical simulations and predictions cannot meet needs of decision makers weighing economic development against the need to protect 
property and life. Disaster risk assessments based on socioeconomics and populations have gained more attention recently as a valuable tool for governments, insurance companies, coastal communities, and policy makers in determining appropriate risk [4,5]. At the end of the last century, natural disaster risk assessment represented a popular component of disaster prevention and mitigation strategies employed globally. Disaster risk and impact assessment was identified as a priority effort in the International Disaster Reduction Strategy [6]. In the 1990s, the U.S. National Oceanic and Atmospheric Administration (NOAA), U.S. Army Corps of Engineers (USACE), and Federal Emergency Management Agency (FEMA) developed a storm surge risk assessment [7] and used it to establish a storm surge disaster level and vulnerability level map [8], disaster risk zoning map, and risk inundation evacuation map [9]. Japan and Europe also conducted impact assessments of storm surge and other hazards on the local economy and vulnerable assets, and developed emergency response and evacuation plans [10-12]. In China, marine disaster statistics have been collected since 1992. At present, most regions have completed risk assessments based on coastal land use classification $[13,14]$ and pilot work on regionalization, disaster prevention, and implementation of a mitigation strategy has been completed in key regions. The national-scale risk assessment is general in nature, however, and lacks specific risk assessments for vulnerable assets. Although it has a certain guiding role in the formulation of national-scale disaster prevention and mitigation strategies, this type of assessment cannot fully meet the needs of decision makers who remain concerned about protecting their most vulnerable assets. Researchers seeking to address these unmet needs have conducted studies on the risk assessment of specific hazards and their effects on vulnerable assets at different scales. For example, Kobyliński [15] conducted a risk assessment on the impact of waves on ships. Quinn et al. [16] carried out a study on the inundation risk of buildings caused by uncertainty in a storm surge time series in extreme weather. Zachry et al. [17] established a risk assessment database using a hypothetical typhoon and discussed the impact of different disaster causal factors on the risk assessment. Kameshwar [18] established a system for a multi-disaster vulnerability risk and resilience assessment of coastal infrastructure. Gill and Malamud [19] evaluated the impact of interactions among 18 kinds of human-made processes and 21 kinds of natural disasters. Xu et al. [20] carried out a joint risk study on typhoon storm surges and rainfall. Rey et al. [5] conducted a tropical cyclone risk assessment on the impact of storm surges of different forward speeds, radius of maximum wind, intensity (category 1-5), landing position, initial water level, and direction. Researchers have assessed the risk of marine disasters primarily from the perspective of weather systems and crude social indicators, using these factors to establish discrete but artificial risk grades. They seldom have considered, however, the differences among vulnerable assets in their hazard resistance and the role of emergency response and recovery capability in risk assessment. Without this additional consideration, it remains difficult to meet the targeted and multilevel requirements of decision makers. Therefore, this study focused on the affected infrastructure as the starting point for building a continuous risk assessment framework. It considered the differences among vulnerable assets in their hazard resistance and the impact of emergency response and recovery capability based on previous risk assessment.

\subsection{Study Area}

The lower Laizhou Bay coastal area of the Bohai Sea, China (abbreviated as lower part of Laizhou Bay) is a key area for oil and gas development, and vegetable greenhouse development, with important on-site industries, such as a fishing port, chemical industry, salt pan, and marine aquaculture (Figure 1). It is an important social and economic entity. The lower part of Laizhou Bay includes the mouth of the bay, which is strongly affected by storm surges and waves [21]. The types of vulnerable assets located in the affected infrastructures are diverse [14], rendering it difficult to prevent and mitigate disasters. Therefore, it is essential to assess the risk to natural and anthropogenic infrastructure 
(which is the disaster-bearing body) in the lower part of Laizhou Bay to protect people's lives and property and to mitigate disaster losses.

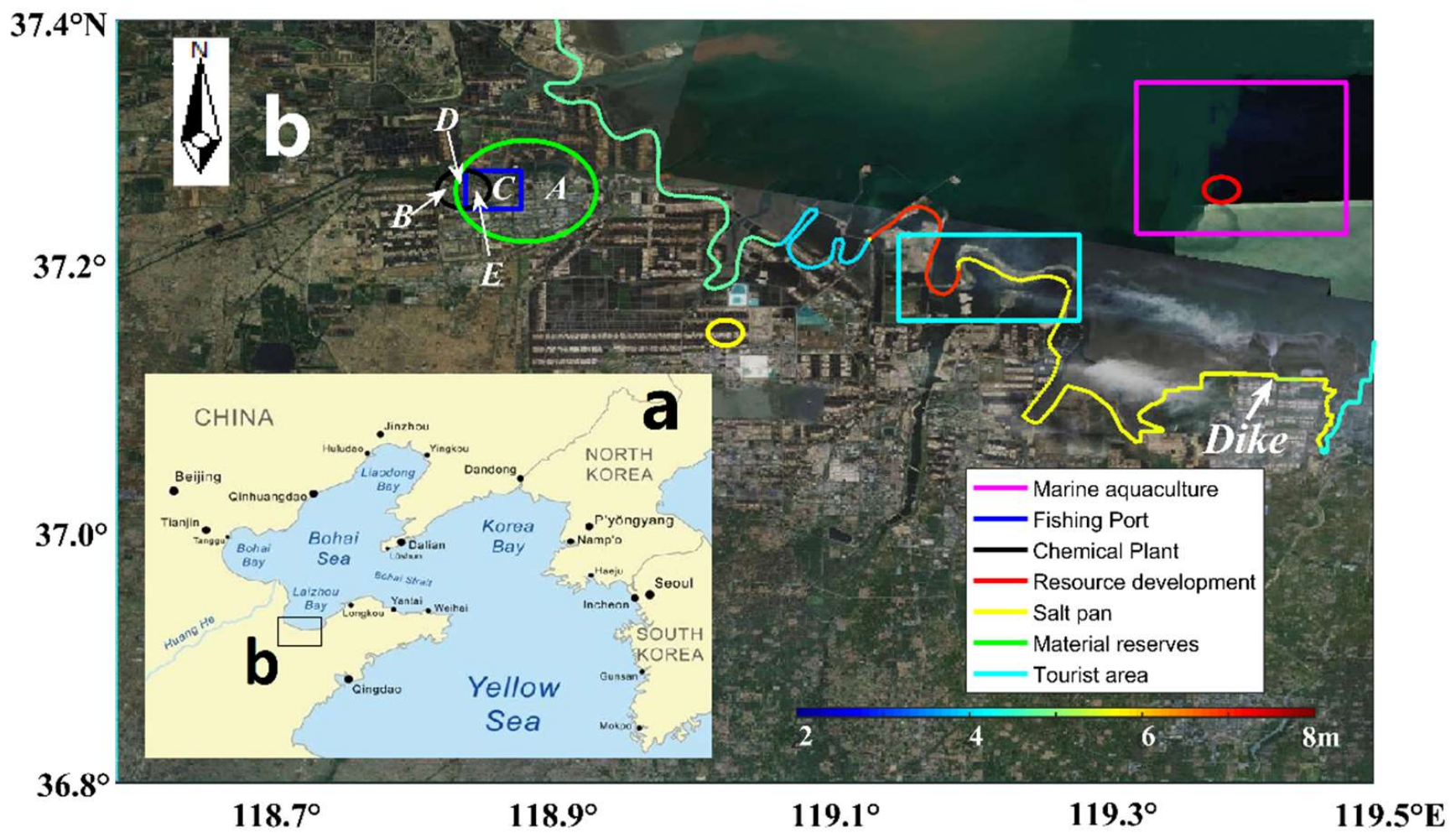

Figure 1. Abstract map of key infrastructure in the lower part of Laizhou Bay. (a) indicates the large study area of the Bohai and Yellow Seas in China, and (b) indicates the specific study area, which is located at the lower Laizhou Bay coastal area of the Bohai Sea. The center position and rough distribution of the infrastructure are given based on surveys. Contour lines in the figure indicate the height of the dike. Letters A-E indicate the key area of the affected infrastructure.

Figure 1 illustrates a schematic diagram of the distribution range of some important affected infrastructure at the lower part of Laizhou Bay. It can be divided into 7 categories, namely marine aquiculture, fishing port, chemical plant, marine ranching, salt pan, material reserves and tourist area. Marine aquiculture and marine ranching are located in the sea. Marine ranching is an important asset of protection and development for marine aquiculture, thus it can be considered more valuable. The tourist area is located in the coastal area and mainly develops a combination of land and sea tourism projects, therefore part of the area is located in the sea (Figure 1 cyan area). The salt pan is located in the land area near the sea (Figure 1 yellow) and connects to the sea through waterways, but the actual elevation is higher. The fishing port and chemical plant are located in an important industrial area and represent a priority area for protection and study, where there is a superposition of multiple impacted affected infrastructures (Figure 1 key areas). To ensure the safety of the area, government agencies established a storage area for disaster relief reserves (the green oval area in Figure 1) on the basis of demonstration and research. The scope of disaster relief reserves (the green circle) refers to the scope that can be directly guaranteed by disaster relief materials and personnel, that is, the scope that can be directly reached by disaster relief materials transported without vehicles, and it is also stipulated that the scope may be exposed to risks of disaster relief materials. Key area A (area A in Figure 1) shows the distribution of petroleum reserves. Key area B displays the distribution of chemical plants. Key area C illustrates the common distribution area of fishing ports and relief reserves. Key area D shows the common area of chemical plants and relief reserves. 
Key area E shows the common distribution area of chemical plants, relief reserves, and fishing ports.

\subsection{Typhoon Dynamics}

Typhoon Lekima (TY1909) formed over the ocean east of the Philippines at 14:00 on 4 August 2019. It strengthened to "typhoon" level at 05:00 by 7 August, and strengthened further to "severe typhoon" level at 17:00, and then climbed to "super-typhoon" level at 23:00, thus achieving a record of three consecutive jumps in one day. Typhoon Lekima then moved northwest and made landfall in the coastal area of Wenling City, Zhejiang province at about 01:45 on 10 August. The maximum wind force near the center was category 16 (super-typhoon level) when it made landfall. After its first landfall, it travelled north along the coastline making landfall again in the coastal area of Huangdao District, Qingdao city, Shandong Province, at about 20:50 on 11 August. The maximum wind force near the center at this time was category 9 (tropical storm level). It mobilized out to sea at Laizhou Bay at about 04:00 on 12 August, maintaining the intensity of a tropical storm, stalled in Laizhou Bay, and was no longer recorded after 11:00 on 13 August. Typhoon Lekima was responsible for the most severe storm surge affecting Laizhou Bay in the past 30 years owing to its strong intensity, long duration, and wide area of impact. The direct economic losses caused by Lekima in China reached CNY 51.53 billion, according to incomplete statistics by the Ministry of Emergency Management. Given the large amount of damage associated with Lekima, it is of practical significance to construct a risk assessment framework based on the distribution of natural and anthropogenic infrastructure along Laizhou Bay and to use Lekima's typhoon storm surge as an example for assessment. This kind of reasonable and accurate risk assessment can provide technical support and reference for decision makers. Based on the above-mentioned research status and disaster distribution characteristics, this paper selects the important affected infrastructure at the lower part of Laizhou Bay as the research object, and establishes a perfect, accurate and rapid assessment system by analyzing the characteristics of various disaster causal factors and affected infrastructure, so as to achieve the purpose of rapid warning and auxiliary decision making in the face of disasters.

\section{Data and Methods}

\subsection{Observed Data}

We used data from tide stations and buoys (Figure 2) for the return period calculation and model verification and risk assessment. The time resolution of the data was $1 \mathrm{~h}$. The base surface of the tide level station conforms to national measurement standards and bears a fixed conversion relationship with mean of sea level, which was converted in this paper when used. The data years of the tidal station WFG for calculating the tide level recurrence period are 2008-2019. Tide stations provide real-time tidal-level observations. Some tide stations also provide real-time wind data. Buoys provide real-time wind and wave data for input into wind verification and wave risk assessment. Wind measurement height is standard at $10 \mathrm{~m}$. Note that the tidal station YKG is an estuary tidal station located inland and can be used for floodplain result verification. We calculated and analyzed the astronomical tide by harmonic analysis of more than one year of measurements from the tide gauge stations. We obtained the storm surge tidal level by subtracting the astronomical tidal level from the observed tidal level [22-24]. The lower limit of the storm surge tidal level was the mean of sea level, which was also the lower limit of the numerical model. The tidal level used in this paper was the water level under fixed mean of sea level, with the superposition of storm surge and astronomical tide $[25,26]$. We did not consider the extreme wave runup statistic (R2\%; e.g., Stockdon et al. [27]). Waves are discussed separately as coupling hazards. 


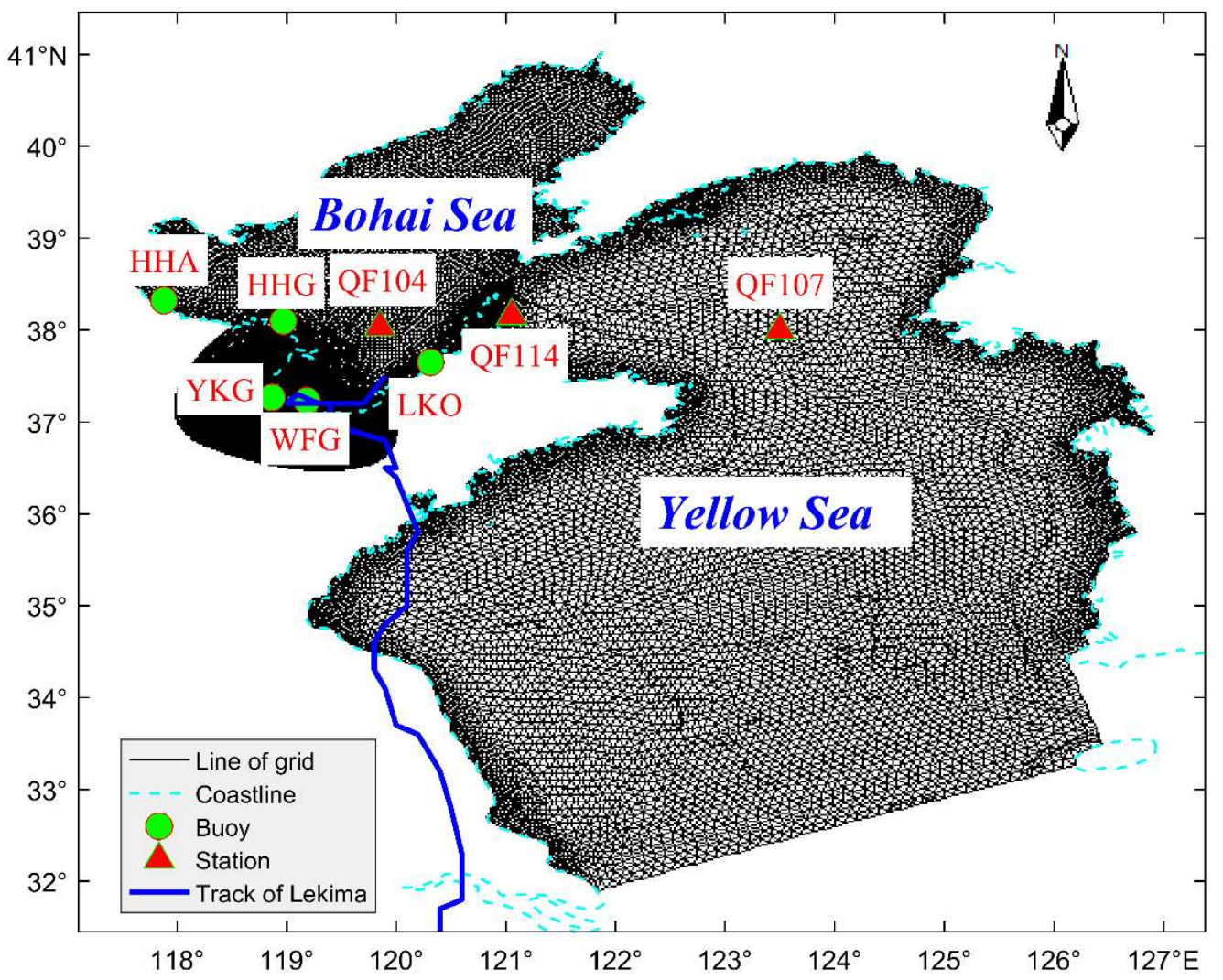

Figure 2. Computed model domains of MIKE21. The path of Typhoon Lekima (TY1909) is indicated by the blue line.

\subsection{Calculation of Return Period}

We used an extreme probability distribution to calculate the return period of tidal levels, but used Pearson III distribution to calculate the return period of waves [28]. Many researchers have attempted to employ other parameter models, such as Weber distribution, Cauchy distribution, generalized extremum distribution, and lognormal distribution, and obtained varying results $[29,30]$. Extreme value distribution is used mostly when all extreme values occur with equal probability, and the Pearson III distribution is adopted when more attention is paid to distributions with a higher probability of extreme values. The extreme value distribution is a frequency curve based on certain theories, including the Gumbel distribution, the Frechet distribution, and the Weibull distribution. The extreme I probability distribution model is used primarily in hydrology [31].

In this paper, we selected the extreme I probability distribution model (Gumbel distribution) to calculate the tidal level return period representing the degree of the hazard generated by the tidal level of the sea. Specifically, the annual extreme high tide levels of WFG tide station from 2008 to 2019 are sorted and brought into Gumbel distribution to obtain the tide level recurrence period. The formula of Gumbel distribution is as follows:

$$
P=\exp \left\{-\exp \left[-\frac{x-\gamma}{\alpha}\right]\right\}
$$

where $P$ is the occurrence probability, $x$ is the occurrence value, $\alpha$ is the scale parameter, and $\gamma$ is the location parameter.

\subsection{Model and Validation}

The MIKE21 model was developed by the Danish Hydraulic Institute. It is a twodimensional free surface flow model widely used in two-dimensional simulations of tidal 
flow, water flow, storm surge, waves, and floods [32]. Many researchers also use MIKE software for storm surge and wave assessment [33-35]. The specific equation and settings are described by the Danish Hydraulic Institute [36-39].

In this study, we chose the MIKE21 model to simulate the storm surge caused by TY1909 Lekima in the Bohai Sea. The specific simulation range is shown in Figure 2. The simulation adopted an unstructured triangular mesh with far to near encryption settings, consisting of 136,340 cells with 68,941 nodes, and a horizontal minimum resolution of $100 \mathrm{~m}$. We derived data on shoreline, water depth, and topography from electronic charts, a Digital Elevation Model (1:50,000 DEM, measurement time 2010-2012), and actual supplementary measurement data, which were unified in a Mercator projection (WGS1984) geographic coordinate system. We obtained dike data from the actual elevation measurement results and simulated the dike-breaking. The dike at the lower part of Laizhou Bay is a mixture of natural and concrete straight dike. The location of the dike is established along the shoreline. The lowest elevation measures about $2.78 \mathrm{~m}$ from the mean of sea level, see Figure 1. The base level used was mean of sea level. To meet the needs of floodplain, we applied the floodplain inundation setting method of Quinn et al. [16]. We adopted tidal level peaks representing 1 in 2 year events as the astronomical tide starting surface for storm surge simulations. The starting surface of the study area was $1.8 \mathrm{~m}$ above mean of sea level. Based on the Courant-Friedrichs-Levy numerical stability condition, we used computational time steps of 0.01 and $60 \mathrm{~s}$ for the minimum and maximum. We specified temperature and salinity to be constant at $18^{\circ} \mathrm{C}$ and $35 \mathrm{psu}$. Storm surges in this model were controlled only by wind stress. Wind stress can be computed according to the following equation:

$$
\vec{\tau}=C_{\mathrm{d}} \rho_{a}\left|\vec{V}_{W}\right| V_{W}
$$

where $C_{\mathrm{d}}$, a drag coefficient dependent on wind velocity, is given by the fitting curve [40], which is fitted to the mid-air pressure profile of Moon et al. [41] based on previous research by Powell et al. [42] and Oey et al. [43].

We obtained reanalyzed wind and atmospheric pressure data from the European Centre for Medium-Range Weather Forecasts (ECWMF reanalyzed data) and retrieved the data as the forced condition of MIKE21 numerical model input after grid interpolation. The wind observation data were collected from stations and buoys HHA, HHG, QF104, QF114, and QF107. Their locations are shown in Figure 2. A comparison of the reanalyzed wind and the observed wind is shown in Figure 3. The figure reveals that the wind velocity and direction essentially agreed except upon the typhoon's entrance to the Bohai Sea, which proved the reanalysis wind could reflect the real wind to a certain extent. Initial and boundary points maintain a tidal level of $1.8 \mathrm{~m}$ above sea level instead of tidal data input and a flow rate of $U_{0}=0, V_{0}=0$ (here $U_{0}$ and $V_{0}$ are the velocities in the initial longitude and latitude directions). The effects of tides, rivers, and wave run up were not modeled. The conditions applied to the open boundaries were a combination of free surface and open wet and dry grid.

The storm surge observation data were collected from five tide stations: HHA, HHG, YKG, WFG, and LKO. Their locations are shown in Figure 2. The MIKE21 mode outputs hourly storm surge data and extreme data of storm surge at tide stations. The model output time is 0:00 on 10 August 2019-23:00 on 13 August 2019. The results of the model agreed well with observations not only in magnitudes but also in phases. The main deviation was caused by local terrain deviation and wind variation, as shown in Figure 4. Note that the curve simulation of the front section of station YKG was quite different from the actual measurement since the station was located in an estuarine area and the floodplain simulation showed that dike-breaking did not occur in the previous period. Therefore, no storm surge data were available at the station YKG for the previous period of the simulation. The change in floodplain height remained basically the same after the dike-breaking, however, the floodplain simulation was accurate to a certain extent. 


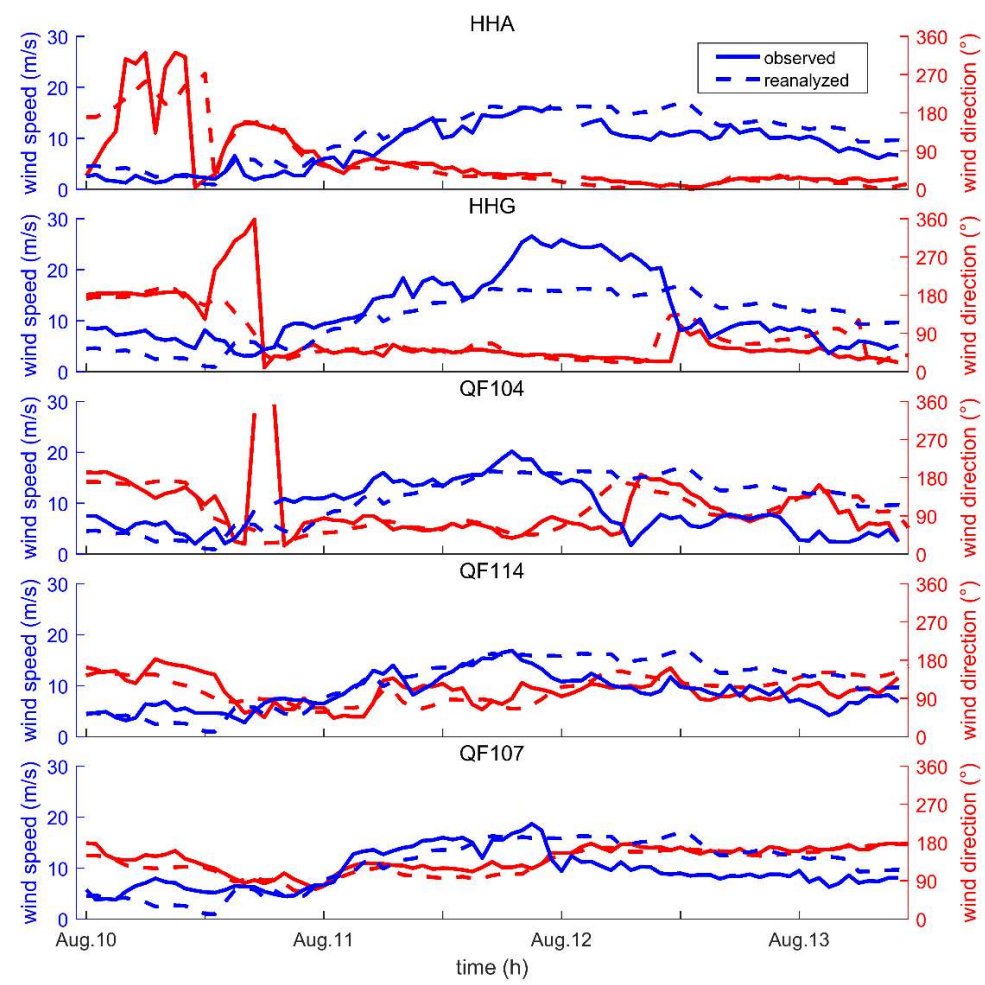

Figure 3. ECWMF reanalyzed data (dashed lines) and observed (solid lines) time series of wind at stations and buoys: HHA, HHG, QF104, QF114, and QF107 induced by Typhoon Lekima (TY1909) in August 2019. The blue line indicates the wind speed and the red line indicates the wind direction.
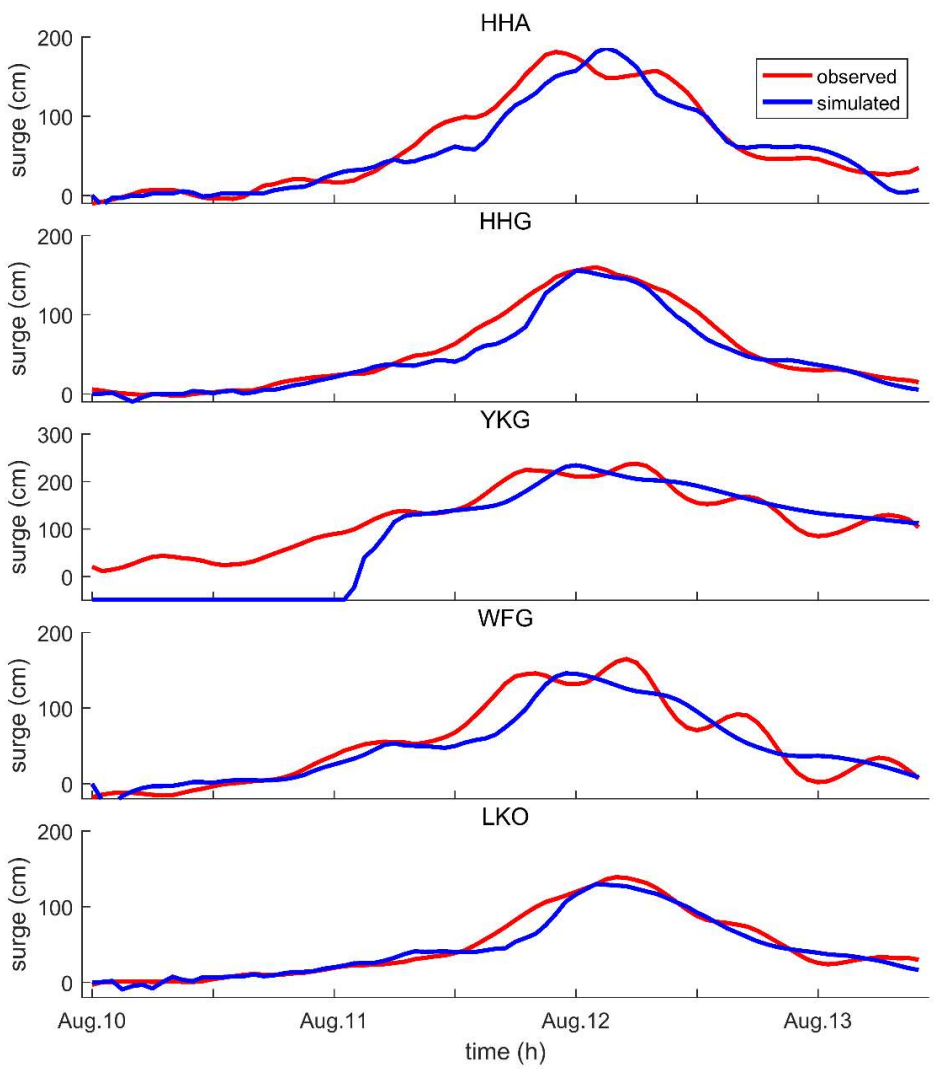

Figure 4. Simulated (blue lines) and observed (red lines) time series of storm surge at tide stations HHA, HHG, YKG, WFG, and LKO induced by Typhoon Lekima (TY1909) in August 2019. 


\section{Risk Assessment Framework}

\subsection{Risk Assessment}

In a risk assessment, there are typically two means of integration. One method of risk assessment considers hazard and vulnerability either by addition [33,44] or multiplication [5,45-47]. A second risk assessment method multiplies the probability of occurrence over time according to the degree of loss [10,16]. Direct statistical calculation methods and indirect correspondence calculation methods can be used to determine the degree of loss. The indirect correspondence calculation methods are usually performed by establishing a functional relationship between the hazard of the disaster causal factor and the loss. This method is easy to perform, but it is difficult to account for the characteristics of the affected infrastructure or other assets. Both types of risk assessment can incorporate the role of emergency response and recovery capability, to a certain extent.

To highlight the characteristics of the affected infrastructure, we carried out a marine disaster risk assessment by combining the hazard associated with disaster causal factors, vulnerability associated with affected infrastructure and emergency response, and recovery capability. A clear definition of risk assessment terms is needed, including risk, hazard, vulnerability, susceptibility, and resilience [5,48]. The definition of risk and risk assessment is derived from the "Terminology on Disaster Risk Reduction," published by the United Nations International Strategy for Disaster Reduction [49]. Risk is defined as a combination of the probability of an event and its negative consequences. The definition of risk assessment is a methodology used to determine the nature and extent of risk by analyzing potential hazards and evaluating existing conditions of vulnerability that together could potentially harm exposed people, property, services, livelihoods, and the environment upon which they depend. According to the definition of risk assessment, risks are determined by hazards, vulnerability, and the related environment without considering the probability of occurrence [50]. The environment refers to the external environment in addition to its own attributes, including the natural external environment and the human-made disaster relief environment (reflecting emergency response and recovery capability). Hazard is defined as a phenomenon or human activity that may cause loss of life, injury, or other health effects; property damage; social and economic disruption; or environmental degradation [5,49]. In this paper, hazard refers to the hazard caused by forces associated with marine disasters. Vulnerability is defined as a measure of the intrinsic susceptibility of an element exposed to a potentially damaging natural phenomena [47], either a long-term stressor or a short-term intense shock. Vulnerability consists of two elements: exposure and susceptibility. Exposure is quantified by the number of elements at risk (damage potential) and susceptibility is defined by the degree of damage (loss) to the asset exposed to the hazard [5]. In this paper, vulnerability refers only to exposure as defined by Rey et al. [5], which is determined by the asset affected by the disaster. In other words, vulnerability is an intrinsic property. In the face of risk, the susceptibility (S) characterized by the sensitivity matrix is understood to represent the exposure of vulnerable assets, the probability of influence $[10,16]$, the relative magnitude of occurrence risk, and sometimes the risk of injury and flooding. It is related to the magnitude of the hazard and the attributes of affected infrastructure. Therefore, the susceptibility matrix can effectively connect hazards and vulnerabilities to measure the response level of different types of infrastructure to different disaster causal factors. The emergency response and recovery capability refers to Dinh et al.'s [33] definition of resilience, which includes the role of material reserves and personnel in disaster response and mitigation, as well as the ability to maintain a significant level of social, economic, environmental, and physical components.

The division of assessment grades (including hazard grades, vulnerability grades, disaster prevention and mitigation capacity, loss grades, or risk grades) or risk weighting coefficient of a factor (or probability of occurrence of an event) usually involves a function analytical method, analytic hierarchy process, expert scoring method, and entropy method. The function analysis method obtains the simple function expression by fitting certain variables directly with the grade or weight, and approximately describes the relationship by 
threshold interval and other restrictions. The expert scoring method uses fixed indicators to determine the weight and evaluation grades. These scores are obtained by scoring according to the best professional judgement of industry experts. For example, the hazard grades of Tsunami and Storm Surge Research Association [12] were scored based on the effect of seawater on humans, and Liu Q et al.'s [13] vulnerability grades were based on the status of land use. This method relies on artificial knowledge. If the recognized grade criteria, basis, and relevant regulations can be identified, the definition of grade will play a guiding role in risk assessment. Analytic hierarchy process refers to the elements involved in a decision and is always decomposed into objectives, principles, and scheme based on qualitative and quantitative weight assignment. The weight is calculated step by step, as with Rey et al.'s [5] vulnerability weight assignment and Liu Q et al.'s [51] calculation of sea level rise [52] risk assessment weight. The entropy method is an objective weighting method that determines the index weight according to the information provided by each index observation value. The weights or assessment grades are obtained using the minimum entropy method based on a large amount of data. If the data sample is small, there may be a large deviation. It is unusual to have a large number of real examples of marine disasters, thus rendering this a rare approach.

In this study, the hazard grade, vulnerability grade, and coefficient of emergency response and recovery capability were established based on the means of return period, characteristics of disaster distribution, types of affected infrastructure, and disaster relief distance, and were continuous by solving functions, normal cumulative distributions, and analytic functions. We established a sensitivity matrix through hierarchical comparative analysis to obtain the evaluation weight. We employed these methods to construct an $m$ $+n$ sensitivity risk assessment framework for multiple types of infrastructure under the influence of different disaster causal factors. Specifically, when $n$ affected infrastructure in the area are affected by $m$ disaster causal factors concurrently, we calculate the risk according to the following steps (Figure 5). Firstly, the hazard of $m$ disaster causal factors in the target area and the vulnerability of $n$ affected infrastructure are calculated. Secondly, the initial risk of $m \times n$ for different disaster causal factors for different affected infrastructure is obtained by matrix multiplication. The initial risk and sensitivity matrix are multiplied by the corresponding element of the matrix to obtain the risk matrix of $m \times n$ elements risk in the area. Fourthly, the combined risk is equal to the risk value of each element in the $m \times n$ risk matrix, which is obtained by using the complementary risk superimposition algorithm after sorting each element risk from largest to smallest. Lastly, the final risk is obtained by combining the coefficient of emergency response and recovery capability. The calculation of hazard, vulnerability, sensitivity matrix and emergency response and recovery capability are described in the next section.

This framework provided a reference for meeting the different requirements of decision makers. The risk calculation formulas are provided in Equations (3) and (4). Note that we conducted the risk calculation for multiple concurrent disaster processes or superimposed infrastructure through complementary risk superimposition.

$$
R=\left(\sum_{m+n}^{\mathrm{com}} R_{m+n}\right) \times C
$$

$\sum_{m+n}^{\mathrm{com}} R_{m+n}=\sum_{m+n}^{\mathrm{com}} H_{m \times 1} \times V_{1 \times n} \cdot S_{m \times n}=R_{1}+\left(1-R_{1}\right) \times R_{2}+\left[1-R_{1}-\left(1-R_{1}\right) \times R_{2}\right] \times R_{3} \cdots$

where $R$ represents the risk of the research area, which can include a single vulnerable asset or multiple superimposed infrastructure; $H$ represents the hazard caused by the disaster causal factors in the research area, which is usually related to the strength of the disaster causal factors, where $m$ represents $m$ disaster causal factors acting together in the study area; $V$ represents the vulnerability of the infrastructure in the research area, which is usually related to the attributes of the infrastructure itself, where $n$ represents the superposition of $\mathrm{n}$ kinds of infrastructure in the same area; $S$ is a coefficient matrix to measure the magnitude of the risk to different types of infrastructure from different disaster causal factors; $m$ represents the number of disaster causal factors acting on the research 
area; and $n$ refers to the number of superimposed infrastructure elements in the research area. $\sum_{m+n}^{\mathrm{com}} R_{m+n}$ is the combined risk, which is obtained by using the complementary risk superimposition algorithm after sorting each element risk from largest to smallest. The $\times$ in $\sum_{m+n}^{\mathrm{com}} H_{m \times 1} \times V_{1 \times n} \cdot S_{m \times n}$ denotes matrix multiplication, while $\cdot$ indicates that the corresponding terms in the matrix are multiplied together. $R_{1}, R_{2}, R_{3} \ldots$ is matrix $R_{m+n}$ sorted into the various risk grades. The risk describes the risk for each type of infrastructure in the region regardless of emergency response capacity. The risk value range [0,1], and the $R_{1} \geq R_{2} \geq R_{3} \cdots$. C represents the emergency response and recovery capability near the research area, which is related to personnel distribution, material reserves, disaster relief distance, and other factors. This factor reduces the risk in the study area, which we have simplified as a coefficient. It is typical to normalize all grade calculations $[4,11,33]$ thus $H$, $V$, and $C$ are all normalized within a value interval of $[0,1]$.

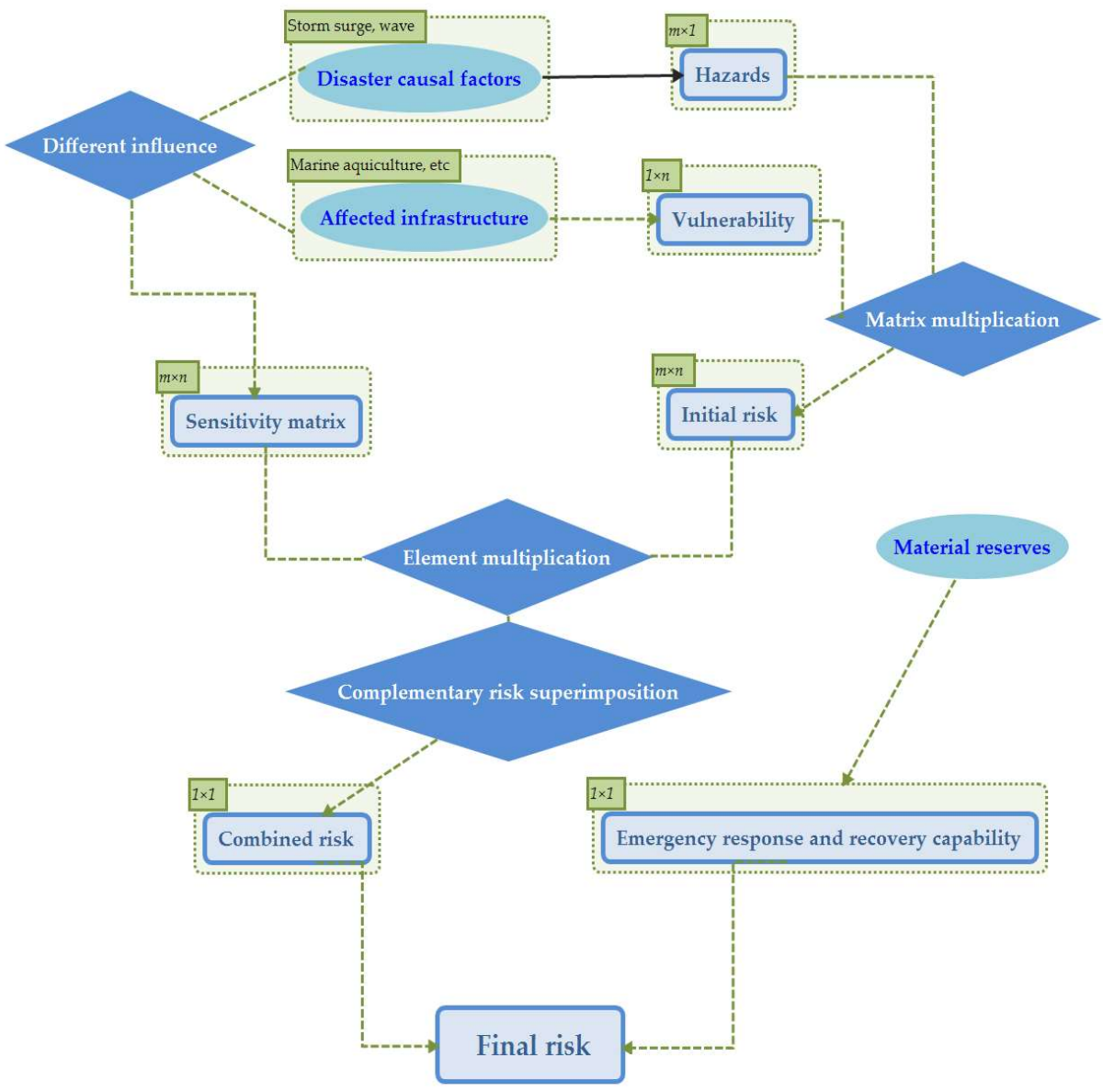

Figure 5. Risk assessment calculation steps.

\subsection{Hazard}

The calculation of hazard grades for storm surges and waves is usually performed in one of two methods. One way is to calculate hazard grades based on observations from a tidal station or buoy representing the hazard to which all of the infrastructure is exposed [14]. Using this method, hazard grades are usually determined using the recurrence period, the local alert situation, and the possibility of causing risks $[10,13,47,53]$. The other method to calculate hazard grades is to use tidal levels and wave heights in the area of the infrastructure for hazard calculation (e.g., Rey et al. [5]). This method generally uses the inundation water depth $[12,33]$ and inundation wave height to calculate hazard grades. The first method usually employs data collected over long time periods. It is suitable for static and long-term statistical hazard calculations based on the point coverage area type. It can obtain the variation rules directly based on long-term observation data, while 
omitting the detailed analysis of each process. It is more applicable to multiyear disaster risk assessments. The second method is used for specific processes and dynamic hazard calculations and is more sensitive to the emotional states of disaster victims (including human beings). With this method, it is usually necessary to supplement the inundation data with numerical models to carry out the risk assessment. If it is used for long-term hazard calculations, the inundation observations and data from the simulation of an annual marine disaster need to be supplemented before risk assessment can be performed again. In practice, however, inundation data are scarce, and the accuracy of the inundation numerical simulation is low. Therefore, this method would be overly complicated for long-term evaluation or implementation. The choice of which approach to employ for calculating the hazard depends on the decision maker's concerns. Moreover, hazard calculations can use a combination of these two methods by setting weight parameters to provide multiangle and multilevel risks.

In this study, we used the risk assessment of storm surge from Typhoon Lekima as an example to demonstrate the two hazard calculation methods. Here, the hazard calculation does not consider the co-occurrence probability of storm surges and wave distribution [54-56], and focuses only on the risk of affected infrastructure when storm surge extremes and wave extremes occur together in a specific extreme event. The continuous hazards are obtained by solving the exponential function based on the value of the disaster causal factor intensity index corresponding to the grade. We calculated the hazard of tidal level (storm surge hazard) based on the tidal height near the infrastructure. The hazard grade of the tidal level was divided by the return period for a tide station, where the infrastructure was located in the sea, and divided according to the inundation depth, where the infrastructure was located on land. We calculated the wave hazard using the effective wave high value representing the buoy instead of the hazard suffered by all of the infrastructure and divided according to the effective wave height reaching the four-color alarm level. Recommendations for grading are given in Table 1 and examples of risk assessment are provided in Section 4.

Table 1. Hazard grade table.

\begin{tabular}{|c|c|c|c|c|c|}
\hline \multirow{2}{*}{$\begin{array}{l}\text { Name } \\
\text { Grade }\end{array}$} & \multicolumn{4}{|c|}{ Numerical Value } & \multirow{2}{*}{$\begin{array}{c}\text { Indicator } \\
\text { Hazard Grade }\end{array}$} \\
\hline & 1 & 2 & 3 & 4 & \\
\hline Hazard value range & $0.75-1.00$ & $0.50-0.75$ & $0.25-0.50$ & $0.00-0.25$ & Standardize the hazard value of $[0,1]$ \\
\hline Tidal level of return period $(\mathrm{m})$ & $\begin{array}{l}3.28-3.52 \\
(100-200)\end{array}$ & $\begin{array}{l}3.04-3.28 \\
(50-100)\end{array}$ & $\begin{array}{l}2.90-3.04 \\
(33.3-50)\end{array}$ & $\begin{array}{l}2.72-2.90 \\
(20-33.3)\end{array}$ & $\begin{array}{l}\text { The tidal level return period is calculated based on the height } \\
\text { of tide gauge station WFG. (The year of return period (a)) }\end{array}$ \\
\hline Depth of inundation (m) & $2.00-3.00$ & $1.20-2.00$ & $0.80-1.20$ & $0.50-0.80$ & $\begin{array}{l}\text { According to the depth of the impact on people of different } \\
\text { ages were divided into grades (Depth of inundation refer to } \\
\text { Tsunami and Storm Surge Research Association [12]). }\end{array}$ \\
\hline $\begin{array}{l}\text { Significant wave height of } \\
\text { four-color alarm (m) }\end{array}$ & $6.00-9.00$ & $4.50-6.00$ & $3.50-4.50$ & $2.50-3.50$ & $\begin{array}{l}\text { Grades are divided according to the four-color alarm levels } \\
\text { effective wave height pairs representing buoy station QF104 }\end{array}$ \\
\hline $\begin{array}{l}\text { Significant wave height of } \\
\text { inundation }(\mathrm{m})\end{array}$ & $1.25-2.00$ & $0.80-1.25$ & $0.50-0.80$ & $0.10-0.50$ & $\begin{array}{l}\text { According to the size of the waves to the different stages of } \\
\text { human impact of the proposed classification. }\end{array}$ \\
\hline
\end{tabular}

We solved analytic exponential functions through grade indices and hazard values. The hazard was continuously transformed by the analytic exponential function over the interval of [0,1] (Figure 6). For values greater than the upper limit of the first grade, we set the hazard values as 1 ; for values less than the lower limit of the fourth grade, we set the hazard values as 0 . 


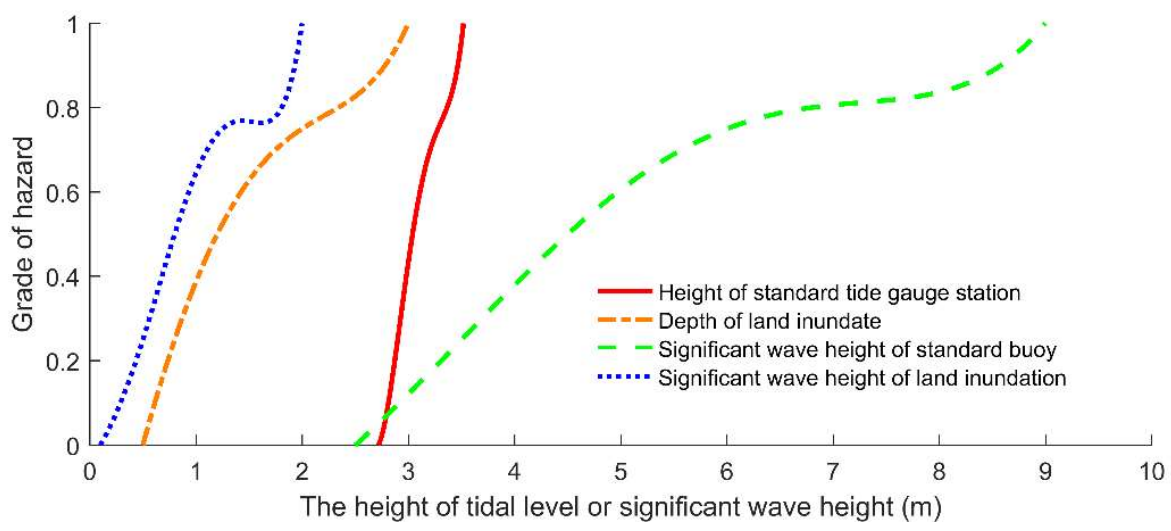

Figure 6. A continuous diagram of four kinds of hazards.

\subsection{Vulnerability}

The vulnerability calculation methods were similar to the hazard calculation methods and could also be divided into two types: using some indicators to replace the vulnerability of a region, and calculating the vulnerability of infrastructure in a specific location based on its actual status. The first method employed population, economy, and other indicators to characterize the vulnerability of a region. For example, Dinh et al. [33] used economic distribution and social components to calculate vulnerability, and Liu Q et al. [51] used population and gross domestic product to calculate vulnerability. The second method used real-world land use status and building distribution to assess vulnerability. For example, Rey et al. [5] selected the distribution of buildings to calculate vulnerability, and Liu $\mathrm{Y}$ et al. [14] used current land use to estimate vulnerability. Typically, the divided method for calculating vulnerability grade is based on relevant regulations or artificial grading. Moreover, certain scholars have considered the influence of the long-term external environment on vulnerability [14,33].

We believed the vulnerability of infrastructure would remain unchanged in a process without considering the material transfer and personnel evacuation in an emergency response and recovery capability, but the vulnerability of the infrastructure would change with the environmental impact over the long term. In the previous situation, the vulnerability of the specific infrastructure was graded based on national standards or universally acknowledged indicators without considering changes in the infrastructure with the environment. We obtained continuous vulnerability values under the assumption that vulnerability does not change in a short period of time, according to national standards and artificial perceptions, and using the cumulative normal distribution base on the ratio of the possible influence amount to the total storage capacity. At the same time, the vulnerability grade was assigned and normalized $[4,12,33]$. The interval of the assignment was $[0,1]$. According to the distribution of infrastructure in the lower part of Laizhou Bay, seven kinds of infrastructure exist (China Marine Disaster Bulletin), and their vulnerability grades were assigned according to different standards. The suggested grades are given in Table 2.

On the basis of the grade, we employed the ratio of the possible influence amount to the total storage capacity to establish the continuous vulnerability relationship through the cumulative normal distribution function. The specific formula is as follows:

$$
V=G_{L}+\left(G_{H}-G_{L}\right) \times D_{C}
$$

where $V$ represents the vulnerability of infrastructure; $G_{H}$ and $G_{L}$ are the upper and lower limits of the value range determined according to the type of infrastructure; and $D_{\mathrm{C}}$ is calculated by the normal cumulative distribution function according to the storage ratio value.

We demonstrated the vulnerability calculation using a fishing port as an example. Fishing ports are divided into four grades according to the classification standards of 
China. The fishing port assigned the highest grade was the central fishing port, with the largest water and road area. Their support facilities could store the greatest amount of fishing boats and related equipment, thus their vulnerability grade was the highest. The vulnerability grades of other levels were reduced accordingly, as shown in Table 2. We determined continuous vulnerability using the standard cumulative normal distribution function according to the corresponding proportion of stored fishing vessels, as shown in Figure 7.

Table 2. Vulnerability grade division of infrastructure.

\begin{tabular}{|c|c|c|c|c|c|}
\hline Name & Evidence of Division & Highest Level & High Level & Medium Level & General Level \\
\hline \multirow{2}{*}{ Marine aquiculture } & Breeding method & Pond culture & Mudflat culture & Cage culture & Raft culture \\
\hline & Value interval & $0.75-1$ & $0.5-0.9$ & $0.25-0.8$ & $0-0.7$ \\
\hline \multirow{2}{*}{ Fishing port } & Fishing grades & Center fishing & First class & Second class & Other class \\
\hline & Value interval & $0.75-1$ & $0.5-0.9$ & $0.25-0.8$ & $0-0.7$ \\
\hline \multirow{2}{*}{ Chemical plant } & Storage or not & Stored & - & - & Not \\
\hline & Value interval & $0.8-1$ & - & - & $0.5-0.8$ \\
\hline \multirow{2}{*}{ Marine ranching } & Breeding ways & Pond culture & Mudflat culture & Cage culture & Raft culture \\
\hline & Value interval & $0.75-1$ & $0.5-0.9$ & $0.25-0.8$ & $0-0.7$ \\
\hline \multirow{2}{*}{ Salt pan } & Abandoned or not & Not & - & - & Abandoned \\
\hline & Value interval & $0.5-1$ & - & - & $0-0.5$ \\
\hline \multirow{2}{*}{ Material reserves } & Degree of importance & Importance & - & - & General \\
\hline & Value interval & $0.5-1$ & - & - & $0-0.8$ \\
\hline \multirow{2}{*}{ Tourist area } & Slack or Busy seasons & Busy season & - & - & Slack season \\
\hline & Value interval & $0.5-1$ & - & - & $0-1$ \\
\hline
\end{tabular}

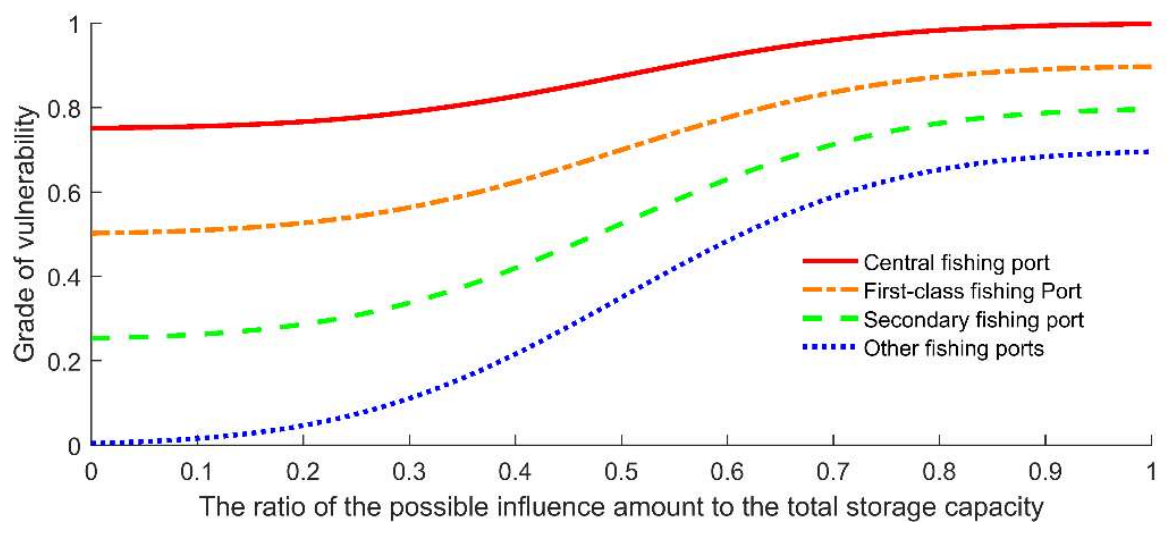

Figure 7. Cumulative normal distribution of vulnerability with the proportion of stored material in different classes of fishing ports.

For the superimposed area of the infrastructure (the key area in Figure 1), we carried out the vulnerability calculation according to the superposition coefficient of the complement. The specific formula is as follows:

$$
V=V_{1}+\left(1-V_{1}\right) \times V_{2}+\left[1-V_{1}-\left(1-V_{1}\right) \times V_{2}\right] \times V_{3} \ldots
$$

where $V$ represents the total vulnerability of this region with a value range [0,1]; and $V_{1}, V_{2}, V_{3} \ldots$ refers to the vulnerability of every type of infrastructure in the region. Its value range is $[0,1]$ and satisfies $V_{1} \geq V_{2} \geq V_{3} \cdots$.

By comparing the calculation formulas for risk (Equations (3) and (4)) and the calculation formulas for vulnerability (Equations (5) and (6)), it became evident that the calculation of vulnerability was equal to the risk when the maximum expression of a single hazard occurred (hazard value $=1$ ) regardless of the sensitivity, emergency response and recovery capability. 


\subsection{Sensitivity Matrix}

There are important differences between regional risk assessment and risk assessment for specific infrastructure. Risk assessment for specific infrastructure needs to examine differences in the resilience of different types of infrastructure to the same hazards. For example, the risks caused by the same submersion depth are different in marine aquiculture and salt pans, even when their vulnerability is the same, due to their differing sensitivities. Regional risk assessment, however, considers factors pertaining to the whole region for risk assessment and usually does not consider sensitivity. Few existing studies have been conducted on risk assessment of the specific infrastructure, and therefore, few existing studies have been conducted on sensitivity. For example, Rey et al. [5] calculated regional vulnerability by considering multiple social indicators but failed to consider the risk differences to these indicators caused by submergence depth. Liu $Q$ et al. [13] employed land use to calculate vulnerability, using only a single class of infrastructure, thus the sensitivity of different kinds of infrastructure to hazards remained unconsidered.

In the study of multiple concurrent disasters, such as the co-occurrence of ocean waves and storm surges, "sensitivity" refers to the difference in risk for the same infrastructure caused by different disaster causal factors. It is worth noting that the sensitivity here refers not to the difference caused by various external potential disaster factors which some scholars consider in regional vulnerability calculation. For example, Dinh et al. [33] used sea level rise, storm surge, rivers, and landslides as factors to measure vulnerability, however, the risk assessment employed a single hazard factor. The differences among the various external factors affecting vulnerability refer not to the sensitivity described in this study.

In this study, we considered the differences in disaster resistance of seven types of infrastructure under the combination of storm surge and ocean wave. We used the comparative study method to assign weight to the relative size of disasters affecting different types of infrastructure under the action of different hazards. The specific steps were as follows: First, we compared the risk of the same infrastructure exposed to different hazards to determine their relative weight. The sum of the weighted values was 1 . Second, we compared the total risk of the different types of infrastructure subjected to all hazards and assigned each a grade. We employed the risk of one type of infrastructure as a reference. For example, in Table 3, the total risk of aquacultural areas subjected to a hazard was defined as 1 , and the other values were assigned a relative value (see the third line in Table 3). Again, the relative total risk was multiplied by the total risk weight. Third, the maximum risk suffered by all forms of infrastructure was defined as 1 (i.e., the risk of a chemical plant to storm surge in the table was 1) and the other weights were standardized (the last two rows in Table 3).

Table 3. Sensitivity matrix calculation table.

\begin{tabular}{|c|c|c|c|c|c|c|c|c|}
\hline & $\begin{array}{c}\text { Marine } \\
\text { Aquiculture }\end{array}$ & Fishing Port & $\begin{array}{c}\text { Chemical } \\
\text { Plant }\end{array}$ & $\begin{array}{c}\text { Marine } \\
\text { Ranching }\end{array}$ & Salt Pan & $\begin{array}{l}\text { Material } \\
\text { Reserves }\end{array}$ & $\begin{array}{c}\text { Tourist } \\
\text { Area }\end{array}$ & Total \\
\hline Relative tidal risk & 0.4 & 0.7 & 0.6 & 0.4 & 0.8 & 0.6 & 0.5 & 4 \\
\hline Relative wave risk & 0.6 & 0.3 & 0.4 & 0.6 & 0.2 & 0.4 & 0.5 & 3 \\
\hline Relative total risk & 1 & 1 & 1 & 1 & 1 & 1 & 1 & 7 \\
\hline Total risk weight & 1 & 0.9 & 1.5 & 1 & 0.8 & 1 & 1.1 & 7.3 \\
\hline \multirow{2}{*}{ Normalized matrix } & 0.444 & 0.700 & 1.000 & 0.444 & 0.711 & 0.667 & 0.611 & \multirow{2}{*}{8.111} \\
\hline & 0.667 & 0.300 & 0.667 & 0.667 & 0.178 & 0.444 & 0.611 & \\
\hline
\end{tabular}

In addition to the above case, sensitivity was reflected in the fact that the risk to infrastructure was different in specific regions and over specific periods of time. For example, during key events, the risks involved should be higher than usual. Therefore, according to the needs of decision makers, a sensitivity coefficient could be designed and directly multiplied by the risk, or one or more levels could be directly increased. 


\subsection{Emergency Response and Recovery Capability}

Emergency response and recovery capability reflects the effectiveness of pre-disaster deployment, emergency response during the disaster, and post-disaster recovery. Predisaster deployment includes preventive construction, disaster relief material deployment, and other activities [33]. The emergency response during the disaster depends on the local storage of relief material and its proportional distribution to the population. Postdisaster recovery includes government assistance and the capacity of personnel to recover from frequent disasters [33]. Few studies have been conducted on emergency response and recovery capability in risk assessment, mainly owing to a lack of sound quantitative methods and the unknown long-term distribution of disaster relief materials, most of which include only policies and temporary distribution of materials. With the development of coastal economies and the frequent occurrence of coastal disasters, however, the reserve of materials and personnel for disaster relief has become an important link in disaster prevention and reduction. Therefore, emergency response and recovery capability must be incorporated into the risk assessment.

This study examined the role of emergency response and recovery capability in disaster assessment based on the real long-term distribution of relief materials in the lower part of Laizhou Bay. Material reserves were established based on field research and demand an analysis in accordance with our disaster prevention and mitigation requirements. The specific locations are distributed near key infrastructures, such as a chemical plant and fishing port in close proximity to schools with high terrain. The storage ratio and quantity are designed according to the demand, and the routes and distances to each disaster-bearing body are designed and calculated. Since physical disaster prevention capabilities such as dams were considered in hazard modeling, this paper regarded only the emergency response and recovery capability determined by the storage of disaster relief materials, the distance to disaster relief, and the number of young adults. Risks are additionally associated with storage of material reserves. As emergency response and recovery capability cannot prevent disaster occurrence, the value interval of the coefficient of the emergency response and recovery capability was $[0.5,1]$. In other words, the emergency response and recovery capability could reduce disaster risk by up to $50 \%$.

Concerning disaster relief material reserves (including personnel and materials) and the distance to disaster relief, the expression of analytic emergency response and recovery capability was constructed as follows:

$$
C=1-0.5 \times\left[\frac{S_{\mathrm{N}} \times\left(1-R_{\mathrm{C}}\right)}{S_{\mathrm{T}}} \times \mathrm{e}^{-\left(D-D_{r}\right) / D_{\mathrm{R}}}\right]
$$

where $C$ is the coefficient of emergency response and recovery capability; $S_{N}$ is the current storage; $S_{\mathrm{T}}$ is the total storage capacity; $S_{\mathrm{N}}$ and $S_{\mathrm{T}}$ are mainly from design standards; $R_{\mathrm{C}}$ refers to disaster relief material risk; $D$ represents the distance between the affected areas to reserve center; and $D_{r}$ denotes direct relief distance (green circle area in the Figure 1). $D_{\mathrm{R}}$ is from the direct relief area outside the distance multiplied by 50 , which assumes that the e fold dimensions of disaster prevention and mitigation equates to 50 times the direct relief distance.

\section{Risk Assessment for Typhoon Lekima Storm Surge}

Based on the risk assessment framework previously constructed combined with MIKE21 numerical simulation results, we developed a risk assessment for the severe typhoon storm surge (Typhoon Lekima's storm surge) that affected the lower part of Laizhou Bay. To conduct the risk assessment, we first determined the extent of the disaster's impact. According to the numerical simulation results, the maximum inundation range is displayed in Figure 8. The figure shows that the inundation area covered all of the infrastructure. Due to coastal elevations, the submergence depth was greatest closer to the seaside and the inundation area measured largest to the west of the lower part of Laizhou Bay. There was no relationship between the tidal level hazard and the specific distribution 
of the infrastructure. There was a relationship with the storm surge caused by the typhoon, which revealed that the distribution of submersion depth in the figure was consistent with the distribution of the tidal level hazard.

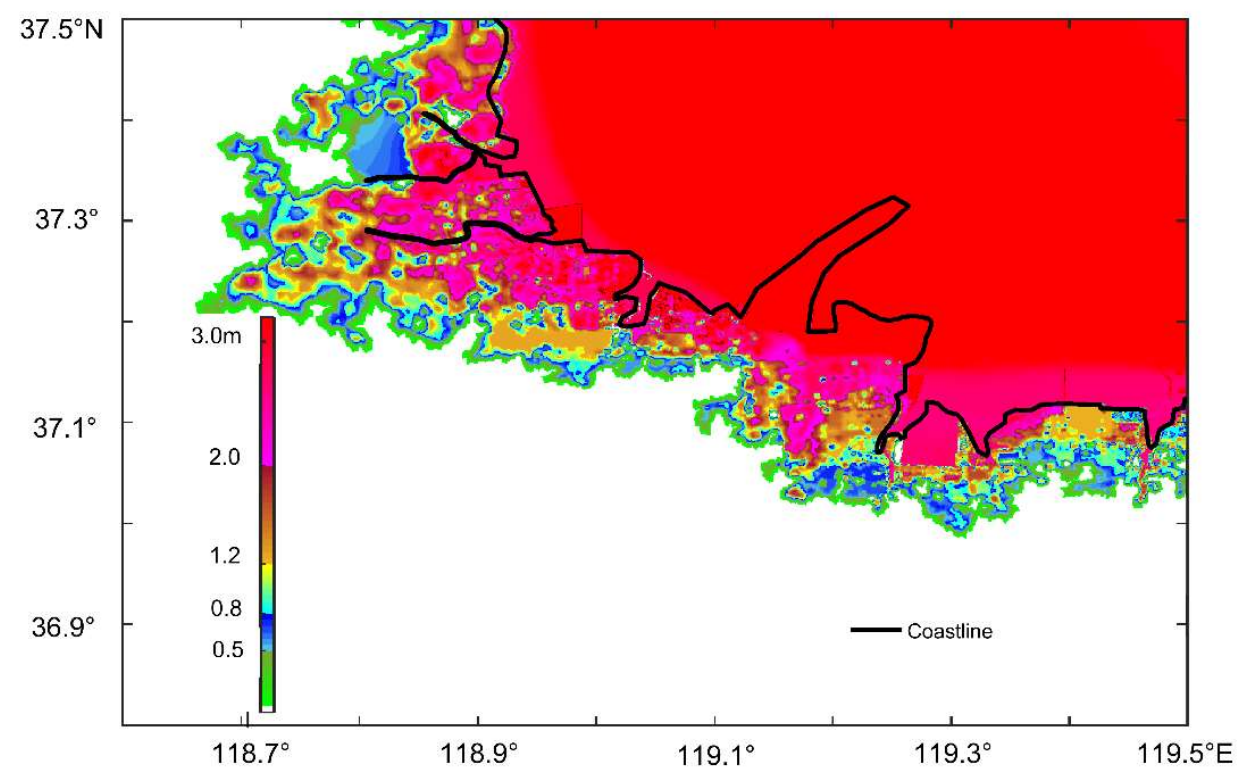

Figure 8. The maximum inundation range of typhoon Lekima storm surge on the lower part of Laizhou Bay.

Hazard calculation: We calculated the tidal level hazard using the simulated tidal level value. We selected the level representing the recurrence period of the tide station WFG for grading at sea tide level hazards and employed the level representing the true submergence depth for grading on land tide level hazards. We used the effective wave height corresponding to the wave hazard grade representing the QF104 buoy to replace the wave hazard of all infrastructure. See Table 4 for the specific hazard grade method. Figure 9 shows the time-varying curves of the different hazard calculation results during Typhoon Lekima, in which the salt pan was a submerged land area and the marine aquaculture was distributed in the sea. The hazard of waves and the tidal level increased gradually as Typhoon Lekima approached the Bohai Sea. The salt pan exhibited a low hazard owing to its higher elevation. The spatial distribution of the maximum hazard of Typhoon Lekima storm surge was essentially consistent with the distribution of tidal level-that is, the closer to the shore, the greater the hazard. The maximum hazard occurred where key areas were superimposed (Figure 10).

Table 4. Hazard and vulnerability table in the Lekima process.

\begin{tabular}{|c|c|c|c|c|c|c|c|}
\hline & $\begin{array}{l}\text { Marine } \\
\text { Aquiculture }\end{array}$ & Fishing Port & Chemical Plant & Marine Ranching & Salt Pan & $\begin{array}{l}\text { Material } \\
\text { Reserves }\end{array}$ & Tourist Area \\
\hline Hazard rating of tide & $\begin{array}{l}\text { Height of } \\
\text { recurrence period }\end{array}$ & $\begin{array}{l}\text { Depth of land } \\
\text { inundate }\end{array}$ & $\begin{array}{l}\text { Depth of land } \\
\text { inundate }\end{array}$ & $\begin{array}{l}\text { Height of } \\
\text { recurrence period }\end{array}$ & $\begin{array}{l}\text { Depth of land } \\
\text { inundate }\end{array}$ & $\begin{array}{l}\text { Depth of land } \\
\text { inundate }\end{array}$ & $\begin{array}{l}\text { Depth of land } \\
\text { inundate }\end{array}$ \\
\hline Hazard rating of waves & \multicolumn{7}{|c|}{$\begin{array}{c}\text { QF104 buoy effective wave high grade replaces all hazard affecting the infrastructure, and the maximum score is } 0.4042 \text { (corresponding } \\
\text { to } 4.1 \mathrm{~m} \text { effective wave high). }\end{array}$} \\
\hline Type & Raft culture & $\begin{array}{l}\text { Center } \\
\text { fishing }\end{array}$ & Stored & Cage culture & $\begin{array}{c}\text { Not } \\
\text { abandoned }\end{array}$ & General & Busy season \\
\hline Value interval & $0-0.7$ & $0.75-1$ & $0.8-1$ & $0.25-0.8$ & $0.5-1$ & $0-0.8$ & $0.5-1$ \\
\hline Storage ratio & 0.5 & 0.5 & 0.5 & 0.5 & 0.5 & 0.5 & 0.5 \\
\hline Vulnerability & 0.350 & 0.875 & 0.900 & 0.525 & 0.750 & 0.400 & 0.750 \\
\hline
\end{tabular}




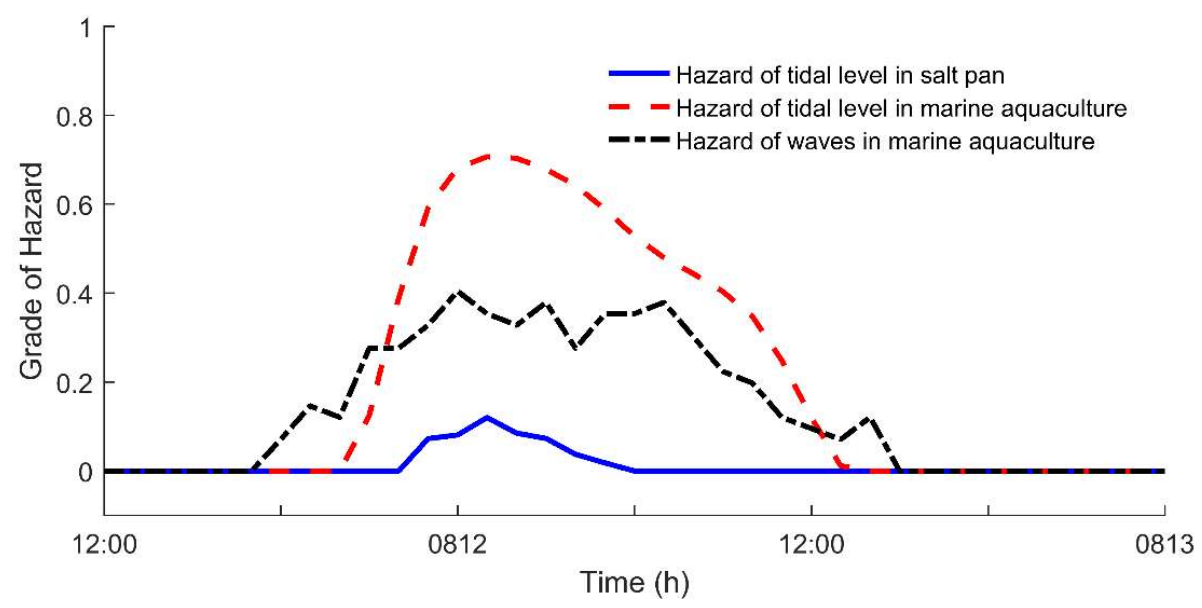

Figure 9. Tidal level and wave hazard curves over time.
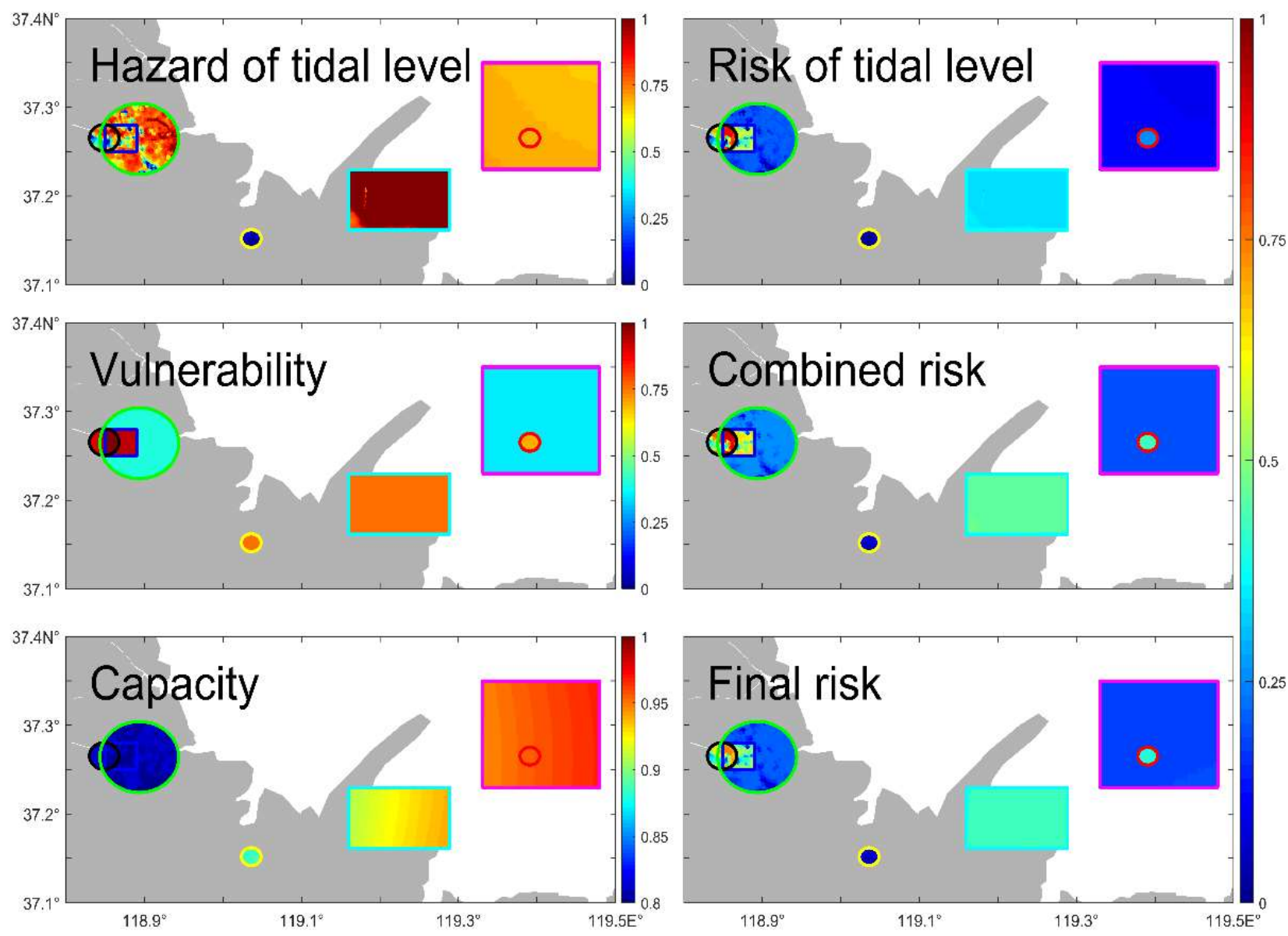

Figure 10. Spatial distribution of risk assessment. The left side includes the hazards associated with individual tidal levels, the vulnerability of infrastructure, and the emergency response and recovery capability. On the right side, the risk of tidal level was calculated using a sensitivity matrix linking the hazard of a tidal level and the vulnerability of infrastructure. Combined risk was calculated using the sensitivity matrix to combine the hazard of tidal levels and waves and vulnerability of infrastructure. The final risk represents an ultimate risk that increases after emergency response and recovery capability.

Hazards are related to disaster causal factors, such as weather systems, and thus changes with time, whereas vulnerability essentially does not change in a process without 
considering the influence of transfer and disaster relief factors. In other words, the spatial distribution of the vulnerability of each infrastructure component remained the same. Therefore, according to the abstract distribution of the infrastructure (Figure 1) and the method of vulnerability calculation, and assuming that the storage ratio was $50 \%$, we calculated the vulnerability of infrastructure in the lower part of Laizhou Bay. The results are shown in Table 4. The infrastructure was discretized according to the numerical model grid. For the area of superimposed infrastructure (the key area in Figure 1), the vulnerability was calculated using Equation (6). The vulnerability of regions A, B, C, D, and E was 0.4, $0.9,0.925,0.9875$, and 0.9925 , respectively. The specific spatial distribution of vulnerability is shown in Figure 10. The area with the highest vulnerability in the figure was the area of superimposed infrastructure-notably, the chemical plant and fishing port in the area were highly vulnerable. We employed the sensitivity matrix to link the maximum hazard and vulnerability caused by Typhoon Lekima in the lower part of Laizhou Bay according to Equation (4). From this, the spatial distribution of individual risk of tidal level (risk of storm surge) and the spatial distribution of comprehensive risk of tidal level and waves (combined risk) can be calculated (Figure 10). The calculated risk should satisfy the value interval $[0,1]$. If the calculated risk value in the study area measured greater than 1 , it was artificially determined to be 1 to ensure the maximum risk of all infrastructure studied was 1.

By comparing the tidal level hazards and risks (Figure 10), we found that the spatial distribution trend of risks in the same infrastructure distribution area was roughly equivalent to the hazards, and the risk of different types of infrastructure was greatly affected by the vulnerability. Combined with the comprehensive risks of waves and tidal levels, we also discovered that the spatial distribution of risk was related to the risk assessment methods adopted by risks of waves and tidal levels. We evaluated the risk of tidal levels according to the spatial distribution grade of numerical simulation results, thus the spatial distribution shared similarity with the spatial distribution of tidal hazard, and the spatial distribution was not uniform. The wave risk grades of all types of infrastructure were replaced by the level corresponding to the measured maximum effective wave height of the buoy QF104, so that their risk spatial distribution remained consistent. Therefore, the addition of the wave risk weakened the spatial distribution of risk inconsistencies. The total risk increased, however, which was consistent with the fact that multiple disasters were more likely to result in losses. The biggest comprehensive risk occurred in tourist areas and where superimposition of key areas were present (key area B-E). Since the tourism area was more sensitive to waves than the superimposed areas, the risks of tourist areas increased more with the addition of wave elements.

We used Equation (7) to calculate the emergency response and recovery capability, as shown in Figure 10. The figure shows that the coefficient of emergency response and recovery capability increased with an increase of distance. When the distance reached e fold dimensions (about equivalent to the marine aquiculture area), the coefficient exceeded 0.95, and the effect of disaster reduction could essentially be ignored. The emergency response and recovery capability largely impacted upon the area close to the material reserves. The risk to superimposed key areas was significantly reduced (Figure 10). As the distance increased, the rescue effort became difficult and the risk changed less, which was consistent with the actual disaster relief situation. Due to the conspicuous effect of disaster mitigation materials on the risk reduction of nearby areas, the establishment of material reserve areas in the vicinity of key infrastructure could play a distinct role in disaster prevention and mitigation in the impact area of historical disasters.

The ultimate risk (final risk) to infrastructure in the lower part of Laizhou Bay caused by the waves and storm surges of Typhoon Lekima measured greatest where key areas were superimposed. The second highest risk was to the tourist areas and marine ranching. The third highest risk was to the disaster relief material areas and the fourth highest was the risk to marine aquaculture, whose value was small owing to the small vulnerability. Salt pan exhibited the smallest risk owing to its low hazard resulting from its high elevation. 
This risk distribution was consistent with the disaster report from Shandong Province, which showed the disaster-related loss of marine aquaculture was greater than that of salt pan. News reports (https://www.sohu.com/a/336596832_120051692, accessed on 16 January 2022) revealed that the fishing port in the key superposition area (see blue circle of Figure 1) was affected by the storm, which caused the nearby road damage and inclination of the wharf; this loss was significant, which was consistent with the calculation result of the risk assessment framework within a certain range.

\section{Discussion}

In this paper, we conducted a risk assessment framework suitable for the lower Laizhou Bay coastal area of the Bohai Sea, China, based on the hazard caused by disaster causal factors, the vulnerability of natural and anthropogenic infrastructure, and the emergency response and recovery capability of disaster relief materials. We assessed the risk of the Typhoon Lekima storm surge using the assessment framework. To clarify the assessment of the Typhoon Lekima storm surge, however, the limitation of the numerical model design must be highlighted. The MIKE model of this paper accounted only for the wind and atmospheric pressure, and did not consider other factors, such as the effect of wave-current coupling. The effect of waves proved insignificant, however, since previous studies on water levels increased up to 3-12\% [57]. The hazard calculation of waves had to replace the hazard suffered by all vulnerable assets, with the hazard measured at the buoy station in the Lekima risk assessment. This method is typically used in long-term general risk assessments and less often in specific process risk assessments. On the basis of previous experience [16], we conducted a floodplain simulation of the Lekima storm surge on the basis of a $1.8 \mathrm{~m}$ base surface. The actual inundation, however, was generated by the superposition of a storm surge and astronomical tides. As a result, the simulated inundation depth and duration revealed some errors with respect to the actual situation. The impact of sea level rise and flood inundation on coastal-affected infrastructure presents an additional key factor in risk assessment, which was absent in this paper and will guide the direction of future research. The space of infrastructure was abstracted and simplified according to the actual spatial position, which produced a number of differences between it and the actual distribution. It was reasonable that vulnerability remained constant in this process and over a short period of time, but long-term vulnerability will vary with the environment [14].

Owing to the characteristics of vulnerable assets, these different assets exhibited different abilities of resistance to different hazards. The risk assessment of a single type of vulnerable asset will differ from the risk assessment of an entire region, thus this difference (i.e., sensitivity) must be considered. With attention paid to disaster prevention and reduction, disaster-prone areas tend to establish a reserve of supporting disaster relief materials and personnel. Therefore, disaster change assessments conducted before and after a disaster that consider the emergency response and recovery capability would be consistent with the trend of current risk research. Different disaster relief materials certainly bear different effects on the emergency response and recovery capability of vulnerable assets. For the convenience of evaluation, we suggested simplifying the evaluation and abstracting the disaster reduction capacity into a coefficient for evaluation. In addition, a risk assessment provides the government and decision makers with universal, targeted, different angles and varying levels of risk regarding the spatial and temporal distribution. Therefore, requirements for specific grade classification are not fixed, and are often determined by decision makers or researchers. Therefore, it is more appropriate to establish a continuous risk assessment grade.

\section{Conclusions}

This paper constructed a simple and feasible risk assessment framework that was suitable for the bottom of Laizhou Bay from the perspective of infrastructure. We classified the natural and anthropogenic infrastructure in the lower part of Laizhou Bay into seven 
categories according to the disaster situation. We obtained the risk to infrastructure by using a sensitivity matrix to combine the hazard grade caused by a storm surge and sea wave with the vulnerability grade of the infrastructure, and multiplying by the abstract coefficient of emergency response and recovery capability. We completed the risk calculation for multiple concurrent effects of disasters or areas with superimposed key infrastructure using complementary risk superposition.

Regarding the sea, hazard grade calculations are based on the return period height of the tidal level and the alert value of the effective wave height of the buoy. On land, this calculation is based on the actual submergence depth and the effective wave height. The hazard grades of the discretization are continuous by the function and solved by the grade indices and hazard values. We calculated vulnerability grades using existing national standards and the abstraction and classification of the real infrastructure in the lower part of Laizhou Bay. The continuous vulnerability relationship was established based on the vulnerability grade, which was utilized to store results proportionally through a cumulative normal distribution function. The sensitivity matrix reflected the differing ability of various types of infrastructure to resist different hazards, which represents the difference between a risk assessment focused on infrastructure and a risk assessment focused on regional characteristics. We calculated the emergency response and recovery capability coefficient by establishing an analytic function built around the storage capacity, distance, and disaster degree.

We conducted a risk assessment of the Typhoon Lekima storm surge using the proposed risk assessment framework and numerical floodplain simulation. The assessment results revealed the ultimate risk distribution of a wave and storm surge were greatest where key areas were superimposed, in tourist areas, and in marine ranching areas. The risk was low for disaster material reserves areas, which bore a high capability for emergency response and recovery. The lowest risk areas were marine aquaculture areas and salt pan areas. The marine aquaculture exhibited a low risk owing to its low vulnerability, and the salt pan contained the lowest risk due to its high elevation. These assessment results were consistent with the publicly available disaster data in terms of spatial distribution. Therefore, this risk assessment framework was suitable for the assessment of marine dynamic disaster process in the lower part of Laizhou Bay.

Focusing research on the infrastructure rendered this risk assessment more refined, and considering the difference of risk before and after emergency response and the recovery capability made risk assessment more realistic. These directions need to be considered and developed in future risk assessment research. The assessment of storm surge risks using this assessment framework provided multiangle and multilevel risk products that provide a suitable reference for disaster emergency response and decision making, which holds great significance for disaster reduction. Particularly, in the context of increasing marine disasters due to global warming and rising sea levels, a sound, accurate and rapid assessment system of multiple disaster-causing elements will effectively reduce the loss of life and property of coastal residents. Moreover, it will play an important role in disaster prevention and mitigation, and support the decision-making process.

Author Contributions: Conceptualization, J.L. and D.M.; Data curation, R.L.; Formal analysis, J.L. and D.M.; Funding acquisition, Y.H.; Investigation, J.L.; Methodology, J.L.; Project administration, Q.L.; Resources, R.L.; Software, J.L.; Supervision, Y.H.; Validation, J.L.; Visualization, J.L.; Writing-original draft, J.L.; Writing-review and editing, D.M. All authors have read and agreed to the published version of the manuscript.

Funding: This study was jointly funded by the National Natural Science Foundation of China, grant numbers U1706216 and 42006027; the Strategic Priority Research Program of the Chinese Academy of Sciences, grant number XDA19060202; and the Key Deployment Project of Center for Ocean Mega-Science, Chinese Academy of Sciences, grant number COMS2019J02.

Institutional Review Board Statement: Not applicable.

Informed Consent Statement: Not applicable. 
Data Availability Statement: The MIKE21 model output used in this study is available at the publicly shared network disk (https:/ / pan.baidu.com/s/17sapqQhOP7CwBWt5Gav7zg, accessed on 16 January 2022 Extraction code: 05SC). The reanalyzed wind data were produced and provided by the European Centre for Medium-Range Weather Forecasts (http:/ / apdrc.soest.hawaii.edu/las/ v6/dataset?catitem=16474, accessed on 16 January 2022). The center position and rough distribution of the infrastructure and DEM are from Department of Natural Resources of Shangdong Province (http:/ / dnr.shandong.gov.cn/, accessed on 16 January 2022). Observational datasets from the tidal station and buoy are not publicly available per provisions of the State Oceanic Administration, but extreme values were available from the Disaster Bulletin (http:/ /ncs.mnr.gov.cn/n1/n127/n134/200 527142944815111.html, accessed on 16 January 2022).

Acknowledgments: The authors are grateful to the North China Sea Marine Forecasting Centre, Ministry of Natural Resources for providing observational data and assisting in model verification.

Conflicts of Interest: The authors declare no conflict of interest.

\section{References}

1. Hou, Y.; Jiang, X.; Liu, Y. China coastal seas under severe sea state: Remote sensing and dynamics studies. Chin. J. Oceanol. Limnol. 2015, 33, 1101-1103. [CrossRef]

2. Nordstrom, K.F. Beaches and Dunes of Developed Coasts; Cambridge University: Cambridge, UK, 2000; pp. 165-191. [CrossRef]

3. Blake, E.S.; Rappaport, E.N.; Landsea, C.W.; Miami, N. The Deadliest, Costliest, and Most Intense United States Tropical Cyclones from 1851 to 2006 (and Other Frequently Requested Hurricane Facts); Hurricanes preparedness facing the reality of more \& bigger storms; NOAA/National Weather Service, National Centers for Environmental Prediction, National Hurricane Center: Miami, FL, USA, 2007. [CrossRef]

4. Pielke, R.A. Normalized hurricane damage in the United States: 1900-2005. Nat. Hazards Rev. 2008, 9, 29-42. [CrossRef]

5. Rey, W.; Mendoza, E.T.; Salles, P.; Zhang, K.; Teng, Y.C.; Trejo-Rangel, M.A.; Franklin, G.L. Hurricane flood risk assessment for the Yucatan and Campeche State coastal area. Nat. Hazards 2019, 96, 1041-1065. [CrossRef]

6. Shi, X.; Tan, J.; Guo, Z.; Liu, Q. A review of risk assessment of storm surge disaster. Adv. Earth Sci. 2013, 28, 866-874.

7. Glahn, B.; Taylor, A.; Kurkowski, N.; Shaffer, W.A. The role of the SLOSH model in National Weather Service storm surge forecasting. Natl. Weather Dig. 2009, 33, 3-14.

8. Watson, C.C. The arbiter of storms: A high resolution, GIS based system for integrated storm hazard modeling. Natl. Weather Dig. 1995, 20, 2-9.

9. Shepard, C.C.; Agostini, V.N.; Gilmer, B.; Allen, T.; Stone, J.; Brooks, W.; Beck, M.W. Assessing future risk: Quantifying the effects of sea level rise on storm surge risk for the southern shores of Long Island, New York. Nat. Hazards 2012, 60, 727-745. [CrossRef]

10. Ferreira, Ó.; Paolo, C.; Clara, A.; Yann, B. Coastal storm risk assessment in europe: Examples from 9 study sites. J. Coast. Res. 2009, 25, 1632-1636.

11. Kleinosky, L.R.; Yarnal, B.; Fisher, A. Vulnerability of Hampton Roads, Virginia to storm-surge flooding and sea-level rise. Nat. Hazards 2007, 40, 43-70. [CrossRef]

12. Tsunami and Storm Surge Research Association. Tsunami and Storm Surge Hazard Map Manual; Cabinet Office of Japan: Tokyo, Japan, 2004. Available online: https://www.pwri.go.jp/icharm/publication/pdf/2004/tsunami_and_storm_surge_hazard_ map_manual.pdf (accessed on 16 January 2022).

13. Liu, Q.; Ruan, C.; Zhong, S.; Li, J.; Yin, Z.; Lian, X. Risk assessment of storm surge disaster based on numerical models and remote sensing. Int. J. Appl. Earth Obs. Geoinf. 2018, 68, 20-30. [CrossRef]

14. Liu, Y.; Lu, C.; Yang, X.; Wang, Z.; Liu, B. Fine-scale coastal storm surge disaster vulnerability and risk assessment model: A case study of Laizhou Bay, China. Remote Sens. 2020, 12, 1301. [CrossRef]

15. Kobyliński, L. Stability of ships: Risk assessment due hazards created by forces of the sea. Arch. Civ. Mech. Eng. 2008, 8, 37-45. [CrossRef]

16. Quinn, N.; Lewis, M.; Wadey, M.P.; Haigh, I.D. Assessing the temporal variability in extreme storm-tide time series for coastal flood risk assessment. J. Geophys. Res. Ocean. 2014, 119, 4983-4998. [CrossRef]

17. Zachry, B.C.; Booth, W.J.; Rhome, J.R.; Sharon, T.M. A national view of storm surge risk and inundation. Weather Clim. Soc. 2015, 7, 109-117. [CrossRef]

18. Kameshwar, S. Multi-hazard Fragility, Risk, and Resilience Assessment of Select Coastal Infrastructure (Doctoral dissertation). In Retrieved from Rice Scholarship; Rice University: Houston, TX, USA, 2017; Available online: https: / scholarship.rice.edu/handle/ 1911/96101 (accessed on 16 January 2022).

19. Gill, J.C.; Malamud, B.D. Anthropogenic processes, natural hazards, and interactions in a multi-hazard framework. Earth-Sci. Rev. 2017, 166, 246-269. [CrossRef]

20. Xu, H.; Xu, K.; Bin, L.; Lian, J.; Ma, C. Joint risk of rainfall and storm surges during typhoons in a coastal city of Haidian Island, China. Int. J. Environ. Res. Public Health 2018, 15, 1377. [CrossRef]

21. Mo, D.; Hou, Y.; Li, J.; Liu, Y. Study on the storm surges induced by cold waves in the Northern East China Sea. J. Mar. Syst. 2016, 160, 26-39. [CrossRef] 
22. Lewis, M.; Horsburgh, K.; Bates, P.; Smith, R. Quantifying the uncertainty in future coastal flood risk estimates for the U.K. J. Coast. Res. 2011, 27, 870-881. [CrossRef]

23. Pugh, D. Changing Sea Levels: Effects of Tides, Weather and Climate; Cambridge University Press: Cambridge, UK, 2004.

24. Zhang, F.; Li, M. Impacts of ocean warming, sea level rise, and coastline management on storm surge in a semienclosed bay. J. Geophys. Res. Ocean. 2019, 124, 6498-6514. [CrossRef]

25. Ruggiero, P. Is the intensifying wave climate of the U.S. Pacific Northwest increasing flooding and erosion risk faster than sea-level rise? J. Waterw. Port Coast. Ocean Eng. 2013, 139, 88-97. [CrossRef]

26. Wahl, T.; Plant, N.G.; Long, J.W. Probabilistic assessment of erosion and flooding risk in the northern Gulf of Mexico. J. Geophys. Res. Ocean. 2016, 121, 3029-3043. [CrossRef]

27. Stockdon, H.F.; Thompson, D.M.; Plant, N.G.; Long, J.W. Evaluation of wave runup predictions from numerical and parametric models. Coast. Eng. 2014, 92, 1-11. [CrossRef]

28. Gumbel, E.J. Statistics of Extremes; Columbia University Press: New York, NY, USA, 1958.

29. Coles, S. An Introduction to Statistical Modeling of Extreme Values; Springer: London, UK, 2001.

30. Walton, T.L. Distributions for storm surge extremes. Ocean Eng. 2000, 27, 1279-1293. [CrossRef]

31. Gumbel, E.J. The return period of flood flows. Ann. Math. Stat. 1941, 12, 163-190. [CrossRef]

32. Warren, I.R.; Bach, H.K. MIKE 21: A modelling system for estuaries, coastal waters and seas. Environ. Softw. 1992, 7, 229-240. [CrossRef]

33. Dinh, Q.; Balica, S.; Popescu, I.; Jonoski, A. Climate change impact on flood hazard, vulnerability and risk of the Long Xuyen Quadrangle in the Mekong Delta. Int. J. River Basin Manag. 2012, 10, 103-120. [CrossRef]

34. Sharifi, F.S.; Ezam, M.; Khaniki, A.K. Evaluating the results of hormuz strait wave simulations using WAVEWATCH-III and MIKE21-SW. Int. J. MArine Sci. Eng. 2012, 2, 163-170.

35. Wang, J.; Xu, S.; Ye, M.; Huang, J. The MIKE model application to overtopping risk assessment of seawalls and levees in Shanghai. Int. J. Disaster Risk Sci. 2011, 2, 32-42. [CrossRef]

36. Danish Hydraulic Institute. MIKE 21 Coastal Hydraulics and Oceanography, Hydrodynamic Module, Reference Manual; DHI Water and Environment: Hørsholm, Denmark, 2008.

37. Panigrahi, J.K.; Tripathy, J.K.; Murty, A. Extremity analysis of storm surge for fixing safe design water level. Nat. Hazards 2011, 56, 347-358. [CrossRef]

38. Kong, X.; College, S.E.; University, D.M. A numerical study on the impact of tidal waves on the storm surge in the north of liaodong bay. Acta Oceanol. Sin. 2014, 33, 35-41. [CrossRef]

39. Siahsarani, A.; Khaniki, A.K.; Bidokhti, A.A.; Azadi, M. Numerical modeling of tropical cyclone-induced storm surge in the gulf of oman using a storm surge-wave-tide coupled model. Ocean Sci. J. 2021, 56, 1-16. [CrossRef]

40. Li, J.; Hou, Y.; Mo, D.; Liu, Q.; Zhang, Y. Influence of tropical cyclone intensity and size on storm surge in the Northern East China Sea. Remote Sens. 2019, 11, 3033. [CrossRef]

41. Moon, I.J.; Ginis, I.; Hara, T. Impact of the reduced drag coefficient on ocean wave modeling under hurricane conditions. Mon. Weather Rev. 2008, 136, 1217-1223. [CrossRef]

42. Powell, M.D.; Vickery, P.J.; Reinhold, T.A. Reduced drag coefficient for high wind speeds in tropical cyclones. Nature 2003, 422, 279-283. [CrossRef]

43. Oey, L.Y.; Ezer, T.; Wang, D.P.; Fan, S.J.; Yin, X.Q. Loop Current warming by hurricane Wilma. Geophys. Res. Lett. 2006, 33 , L08613. [CrossRef]

44. Maskrey, A. Disaster Mitigation: A Community Based Approach; Oxfam: Oxford, UK, 2019.

45. Bronstert, A. Floods and climate change: Interactions and impacts. Risk Anal. 2013, 23, 545-557. [CrossRef]

46. Plate, E.J. Flood risk and flood management. J. Hydrol. 2002, 267, 2-11. [CrossRef]

47. Tingsanchali, T.; Karim, M.F. Flood hazard and risk analysis in the southwest region of Bangladesh. Hydrol. Processes 2005, 19, 2055-2069. [CrossRef]

48. Merz, B.; Hall, J.; Disse, M.; Schumann, A. Fluvial flood risk management in a changing world. Nat. Hazards Earth Syst. Sci. 2010, 10, 509-527. [CrossRef]

49. UNISDR. 2009 UNISDR-Terminology on Disaster Risk Reduction; UNISDR: Geneva, Switzerland, 2009; Available online: https: / / www.undrr.org/publication/2009-unisdr-terminology-disaster-risk-reduction (accessed on 16 January 2022).

50. Blaikie, P.; Cannon, T.; Davis, I.; Wisner, B. At Risk: Natural Hazards, People's Vulnerability and Disasters; Routledge: London, UK, 1994.

51. Liu, Q.; Li, J.; Ruan, C.Q.; Yin, Z.H.; Jiao, Y.; Sun, Q.; Lian, X.H.; Zhong, S. Risk assessment and zoning of sea level rise in Shandong Province. J. Oceanol. Limnol. 2019, 37, 2014-2024. [CrossRef]

52. Church, J.A.; White, N.J. A 20th century acceleration in global sea-level rise. Geophys. Res. Lett. 2015, 33, 313-324. [CrossRef]

53. Haigh, I.D.; Nicholls, R.; Wells, N. A comparison of the main methods for estimating probabilities of extreme still water levels. Coast. Eng. 2010, 57, 838-849. [CrossRef]

54. Michele, C.D.; Salvadori, G.; Passoni, G.; Vezzoli, R. A multivariate model of sea storms using copulas. Coast. Eng. 2007, 54, 734-751. [CrossRef]

55. Zhai, J.; Yin, Q.; Dong, S. Co-occurrence probability of typhoon surges affecting multiple estuaries in the northern coastal region of Taiwan. Reg. Stud. Mar. Sci. 2020, 42, 101582. [CrossRef] 
56. Porcu, F.; Arago, L.; Aguzzi, M.; Valentini, A.; Sabatino, S.D. Extreme Wave Events Attribution Using ERA5 Datasets for Storm-surge Studies in the Northern Adriatic Sea; EGU2020: Munich, Germany, 2020.

57. Orton, P.; Georgas, N.; Blumberg, A.; Pullen, J. Detailed modeling of recent severe storm tides in estuaries of the New York City region. J. Geophys. Res. Ocean. 2012, 117, C09030. [CrossRef] 